BMC

Evolutionary Biology

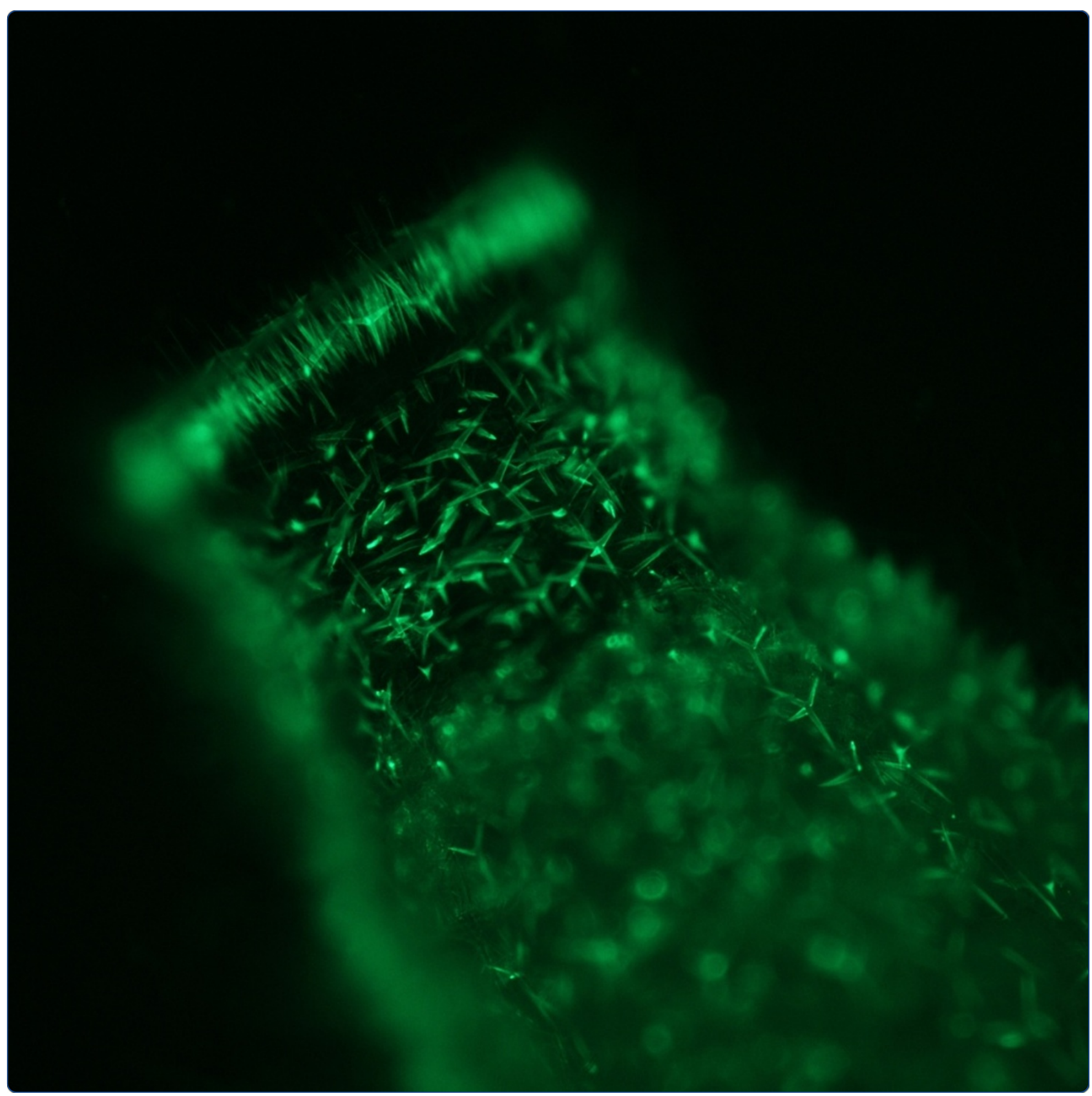

Calcareous sponge genomes reveal complex evolution of a-carbonic anhydrases and two key biomineralization enzymes

Voigt et al. 


\title{
Calcareous sponge genomes reveal complex evolution of a-carbonic anhydrases and two key biomineralization enzymes
}

Oliver Voigt ${ }^{*}$, Marcin Adamski ${ }^{2}$, Kasia Sluzek ${ }^{1}$ and Maja Adamska ${ }^{2}$

\begin{abstract}
Background: Calcium carbonate biominerals form often complex and beautiful skeletal elements, including coral exoskeletons and mollusc shells. Although the ability to generate these carbonate structures was apparently gained independently during animal evolution, it sometimes involves the same gene families. One of the best-studied of these gene families comprises the a- carbonic anhydrases (CAs), which catalyse the reversible transformation of $\mathrm{CO}_{2}$ to $\mathrm{HCO}_{3}^{-}$and fulfill many physiological functions. Among Porifera -the oldest animal phylum with the ability to produce skeletal elements- only the class of calcareous sponges can build calcitic spicules, which are the extracellular products of specialized cells, the sclerocytes. Little is known about the molecular mechanisms of their synthesis, but inhibition studies suggest an essential role of CAs. In order to gain insight into the evolution and function of CAs in biomineralization of a basal metazoan species, we determined the diversity and expression of CAs in the calcareous sponges Sycon ciliatum and Leucosolenia complicata by means of genomic screening, RNA-Seq and RNA in situ hybridization expression analysis. Active biomineralization was located with calcein-staining.

Results: We found that the CA repertoires of two calcareous sponge species are strikingly more complex than those of other sponges. By characterizing their expression patterns, we could link two CAs (one intracellular and one extracellular) to the process of calcite spicule formation in both studied species. The extracellular biomineralizing CAs seem to be of paralogous origin, a finding that advises caution against assuming functional conservation of biomineralizing genes based upon orthology assessment alone. Additionally, calcareous sponges possess acatalytic CAs related to human CAs X and Xl, suggesting an ancient origin of these proteins. Phylogenetic analyses including CAs from genomes of all non-bilaterian phyla suggest multiple gene losses and duplications and presence of several CAs in the last common ancestor of metazoans.

Conclusions: We identified two key biomineralization enzymes from the CA-family in calcareous sponges and propose their possible interaction in spicule formation. The complex evolutionary history of the CA family is driven by frequent gene diversification and losses. These evolutionary patterns likely facilitated the numerous events of independent recruitment of CAs into biomineralization within Metazoa.
\end{abstract}

Keywords: Alpha carbonic anhydrase, Calcareous sponges, Biomineralization, Evolution

\footnotetext{
* Correspondence: oliver.voigt@lmu.de; maja.adamska@sars.uib.no

${ }^{1}$ Department of Earth and Environmental Sciences,

Ludwig-Maximilians-Universität München, Richard-Wagner-Street 10, 80333

München, Germany

${ }^{2}$ Sars International Centre for Marine Molecular Biology, University of Bergen,

Thormøhlensgt. 55, Bergen 5008, Norway
} 


\section{Background}

Carbonate skeletons are formed in many animal phyla. The ability to form calcium carbonate skeletal elements apparently evolved several times independently, but, nonetheless, a core set of certain genes seems to be involved in carbonate biomineralization in different animal groups [1,2]. Components of this 'biomineralization toolkit' could already have been present in the last common ancestor of Metazoa, or gained their biomineralizing function several times independently from suitable precursor proteins [2]. One of the best-studied components of the 'biomineralization toolkit' [3-6] is probably the gene family of $\alpha$-carbonic anhydrases (CAs). CAs are metalloenzymes requiring zinc, which is usually bound by three distinct histidine residues; the proteins catalyse the reversible reaction of $\mathrm{CO}_{2}$ and water to $\mathrm{HCO}_{3}^{-}$and $\mathrm{H}^{+}$[7]. With this function CAs also are involved in a number of other metabolic processes, such as $\mathrm{CO}_{2}$ transport or $\mathrm{pH}$ - and ion-regulation [8,9], and different CAs with specific functions are usually present in a species' genome. In mammals, for example, there are up to 16 CAs (including three acatalytic forms referred to as CA-related proteins or CARPs), which are secreted, membrane-bound, cytosolic or mitochondrial proteins [10-12]. Specialized forms of CAs have been shown to be key elements in the formation of carbonate skeletons in many different invertebrate animal phyla, including sponges [3,13-16]. Jackson and co-workers [3] reported the involvement of $\mathrm{CA}$ in the formation of the basal carbonate skeleton of the demosponge Astrosclera willeyana. While several other sponges can form such basal carbonate skeletons in addition to or in place of their siliceous spicules, only sponges from one of the four currently recognized sponge classes, the calcareous sponges (Class Calcarea), are capable of producing calcite spicules, which is a synapomorphy of this class [17]. The calcite spicules of Calcarea constitute a substantial part of their body weight and, by supporting the soft tissue, enable the growth of larger sponge bodies. Therefore, calcite spicule formation has to be considered a key innovation of this sponge group, which triggered the radiation of calcarean diversity we observe today.

Depending on the number of rays, the calcitic spicules can be categorized into diactines, triactines and tetractines [17], which are formed respectively by two, six or seven specialized cells, the sclerocytes [18-20]. Each spicule grows in an organic sheath of unknown composition, within an extracellular space initially sealed by septate junctions between the involved sclerocytes [21]. The secretory activity of these cells and their movement controls spicule growth (Figure 1a [20]). Among sclerocytes, the so-called "founder cell" promotes growth of the actine tip, while deposits from the "thickener cell" thicken the spicule [18-20]. Little is known about the molecular mechanisms of spicule formation by sclerocytes. However, as in other invertebrates, CA seems to play an important role in this process in calcareous sponges: Spicule formation is ceased or reduced by the application of specific CA-inhibitors to living calcareous sponges [22], but the CAs were not characterized. Attempts to extract or characterize CA-proteins from the calcareous sponge $S$. ciliatum have not been successful [22]. Only recently, a CA of another calcareous sponge has been described and a role in spicule formation and dissolution proposed $[23,24]$. However, various CAs can usually be found in metazoan genomes, and often more than one CA can be linked to biomineralization in corals (e.g. $[11,25])$, molluscs (e.g. $[6,26])$ and urchins (e.g. $[4,13])$.

In this study, we aimed to describe the CA-repertoire of calcareous sponges and identify the CAs involved in spicule formation in order to gain further insight into the evolution of carbonate biomineralization in nonbilaterian animals. We investigated the CAs present in the genome and transcriptome of the emerging model system Sycon ciliatum (Class Calcarea, Subclass Calcaronea, Order Leucosolenida, Family Sycettidae) and a second species, Leucosolenia complicata (Class Calcarea, Subclass Calcaronea, Order Leucosolenida, Family Leucosoleniidae) [27-29]. Active biomineralization was detected by calcein staining methods and correlated with expression data from RNA in-situ hybridization and RNA-seq analyses. Phylogenetic analyses with CAs from genomes of all non-bilaterian phyla let us draw conclusions about the evolution of CA proteins in calcareous sponges and in Metazoa in general.

\section{Results}

\section{Calcein staining experiments}

S. ciliatum is a typical syconoid sponge, with a tube-like body and an apical oscular opening. In the oscular region, the sponge wall is thin. Below this, the sponge wall widens, with tubes arranged radially around the central atrial cavity, the so-called radial tubes. Four spicule types can readily be distinguished in the species (e.g. [18]): (1) long, slender diactines, forming a palisade-like fringe around the osculum; (2) smaller, curved diactines, occurring as tufts on the distal ends of the radial tubes; (3) triactines, supporting the radial tubes and the atrial wall; (4) tetractines, supporting the atrial wall, with a forth ray reaching into the central cavity (Figure $1 \mathrm{~b}, \mathrm{c}$ ). Growing spicules were detected by exposing live S. ciliatum sponges to a calcein disodium solution in seawater for 3 , 18 or $24 \mathrm{~h}$. We observed isolated spicules, sections and complete specimens from these treatments (Figure 1b-c). Isolated spicules from calcein treated sponges largely confirmed results from another Sycon species [30] and observations of spicule formation by Woodland [18] and Minchin [19]. Results show that after an initial phase 

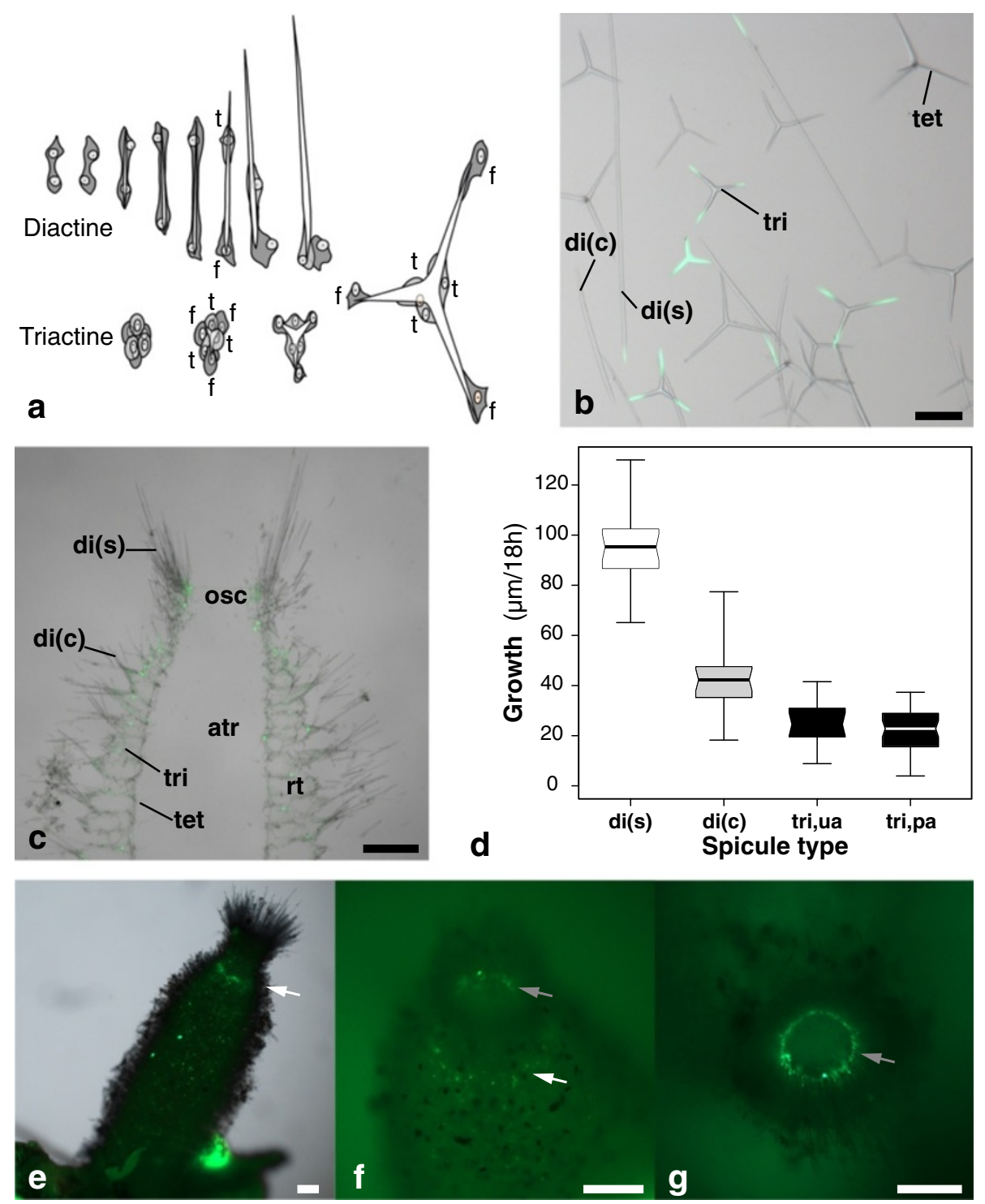

Figure 1 Spicules and their formation in S. ciliatum. (a) Formation of diactines and triactines by sclerocytes in calcareous sponges (redrawn from [18,19]). (b) isolated spicules; scale bar: $100 \mu \mathrm{m}$. (c) skeletal arrangement; scale bar: $250 \mu \mathrm{m}$. (d) Spicule growth in $18 \mathrm{~h}$ observed in three spicule types of S. ciliatum. (e-g) Location of spicule formation in S. ciliatum (calcein disodium staining). Single spicules are formed all over the sponge body, with two regions of denser spicule formation: (1) the radial tube formation zone (white arrow, e) and the proximal tips of the slender diactines of the osculum (inside the osculum, grey arrow: f, g); scale bars: $250 \mu \mathrm{m}$. b,c,e: light microscopic images overlayed with fluorescence microscope images. f,g: fluorescence microscope images. Abbreviations: di(c) curved diactines from the distal end of the radial tubes; di(s): slender diactines of the oscular fringe; f: founder cell; t: thickener cell; tri: triactines; tet: tetractines.

diactine growth is restricted to the proximal actine, and triactines and tetractines grow at their tips, in both cases due to the activity of the founder cells (Figure 1a,b). A second band of calcite deposition on diactines, previously reported and interpreted as the thickening activity of later stage diactines [30], could not be observed. Labeled triactines of S. ciliatum sometimes provided a previously undocumented calcite precipitation pattern. In triactines, distinctions between the so-called unpaired actine, pointing to the distal end of the radial tube, and the two paired actines can be made (Additional file 1). The angle between the paired actines differs from the angle between the paired and the unpaired actines. Also, frequently, a stronger calcite deposition was detected at the unpaired angle where the paired rays contact (Additional file 1).

We calculated the spicule formation rates for three spicule types (the two diactines and triactines) by measuring the fluorescent signal for 15-22 spicules per type from small syconoid sponges incubated $18 \mathrm{~h}$ in calcein. 
Tetractines were omitted because their length was difficult to measure in spicule preparations. In triactines, paired and unpaired rays were considered separately. Growth rates differed considerably between spicule types (Figure 1d). The slender diactines showed the fastest growth (mean growth rate of $5.3 \mu \mathrm{m} / \mathrm{h}$ ), followed by curved diactines (mean growth rate of $2.5 \mu \mathrm{m} / \mathrm{h}$ ). The slowest growth was observed for triactines (mean growth rate of $1.4 \mu \mathrm{m} / \mathrm{h}$ for paired, $1.2 \mu \mathrm{m} / \mathrm{h}$ for the unpaired ray). Observations of complete sponges revealed that active spicule formation occurred all over the sponge body (Figure 1e), but was densely concentrated in two apical regions: (1) at the lower oscular region, where new radial tubes are formed (Figure 1e, f), and (2) in the proximal end of the palisade-like oscular slender diactines (Figure 1f,g).

\section{CA repertoire of calcareous sponges}

Genome-wide screening revealed the presence of nine CAs in S. ciliatum (SciCA1-9, Table 1) and six CAs in $L$. complicata (LcoCA1-6, Table 1). They fall into three not closely related clades in our phylogenetic trees (CAL IIII, Figure 2), which are described in more detail below. Note that the numbering of CAs in both species does not imply gene orthology. The CA sequences were screened for the presence of signal peptides with SignalP 4.0 [31] and presence of the three zinc-binding histidines, considered to be required for the catalytic function of CA (e.g. [7,9]). Furthermore, we checked for terminal transmembrane domains using TMHMM-2.0 [32] and predicted the subcellular localisation of the protein using Target P 1.1 [33] (see Additional file 2 for protein sequences).

The calcarean clade CAL I contains one CA from each species (SciCA9 and LcoCA6, respectively), both of which are extraordinary large CAs (L-CAs), having 1171-1172 amino acids (AAs) compared to the remaining calcarean CAs proteins, which range between 265 and 348 AAs (Table 1). The L-CA possesses a signal peptide, suggesting the enzyme may be secreted. In the $\mathrm{N}$-terminal CA domain of L-CAs, the first zinc-binding histidine is replaced by arginine and the third by glutamine. The same substitutions occur in the closely related (Figure 2) sea urchin CARP (Spu XM_779703) and in human CARPs CA X and CA XI. In the human CARPs these alterations of the zinc-binding sites are the cause of the catalytic inactivity [12]. Therefore, the L-CA proteins also probably lack CA activity. L-CAs also share additional substitutions with the urchin and human CARPs CA X and CA XI (four to five substitutions) and human CARP CA VIII (three substitutions) in 15 sites (Additional file 3) that were previously reported to be conserved among active CAs [9]. The C-terminal half of the L-CAs contain a domain with similarity to vonWillebrandt factor domains (Pfam [34]: Family VWA_2, Clan CL0128), and a domain with similarity to immunoglobin (Pfam [34]: Family Ig_2, Clan CL0011) (Figure 2, green and yellow boxes in scheme, respectively).

Table 1 Properties of CAs in S. ciliatum and L. complicata

\begin{tabular}{|c|c|c|c|c|c|c|}
\hline $\mathrm{CA}$ & Accession & $\begin{array}{l}\text { Coding sequence } \\
\text { ID (Compagen) }\end{array}$ & $\begin{array}{l}\text { Amino acid } \\
\text { length }\end{array}$ & $\begin{array}{l}\text { Signal } \\
\text { peptide }\end{array}$ & $\begin{array}{l}\text { Terminal transmembrane } \\
\text { domain }\end{array}$ & $\begin{array}{l}\text { Presence of } 3 \text { zinc } \\
\text { binding domains }\end{array}$ \\
\hline \multicolumn{7}{|l|}{ S. ciliatum } \\
\hline SciCA1 (scl-CA1) & LN609531 & sctid70372 & 332 & no & no & all \\
\hline SciCA2 (scl-CA2) & LN609532 & sctid21624 & 332 & yes & yes & all \\
\hline SciCA3 & LN609533 & sctid79452 & 316 & yes & yes & all \\
\hline SciCA4 & LN609534 & sctid52059 & 313 & yes & yes & $\mathrm{H} 1, \mathrm{H} 2$ \\
\hline SciCA5 & LN609535 & sctid78781 & 322 & yes & yes & all \\
\hline SciCA6 & LN609536 & sctid91373 & 310 & yes & no & all \\
\hline SciCA7 & LN609537 & sctid82357 & 327 & yes & no & all \\
\hline SciCA8 & LN609538 & sctid21623 & 348 & yes & yes & all \\
\hline SciCA9 (L-CA) & LN609539 & sctid19114 & 1171 & yes & no & $\mathrm{H} 2$ \\
\hline \multicolumn{7}{|l|}{ L. complicata } \\
\hline LCoCA1 (scl-CA1) & LN609540 & Ictid94802, Ictid95538* & 265 & no & no & all \\
\hline LCOCA2 & LN609541 & Ictid78751 & 319 & yes & yes & all \\
\hline LCOCA3 (scl-CA2) & LN609542 & Ictid114957 & 326 & yes & yes & all \\
\hline LCOCA4 & LN609543 & Ictid61203, Ictid80506* & 343 & yes & no & all \\
\hline LCOCA5 & LN609544 & Ictid89007, Ictid89853*, Ictid88526** & 281 & no & no & all \\
\hline LCoCA6 (L-CA) & LN609545 & Ictid17923 & 1172 & yes & no & $\mathrm{H} 2$ \\
\hline
\end{tabular}




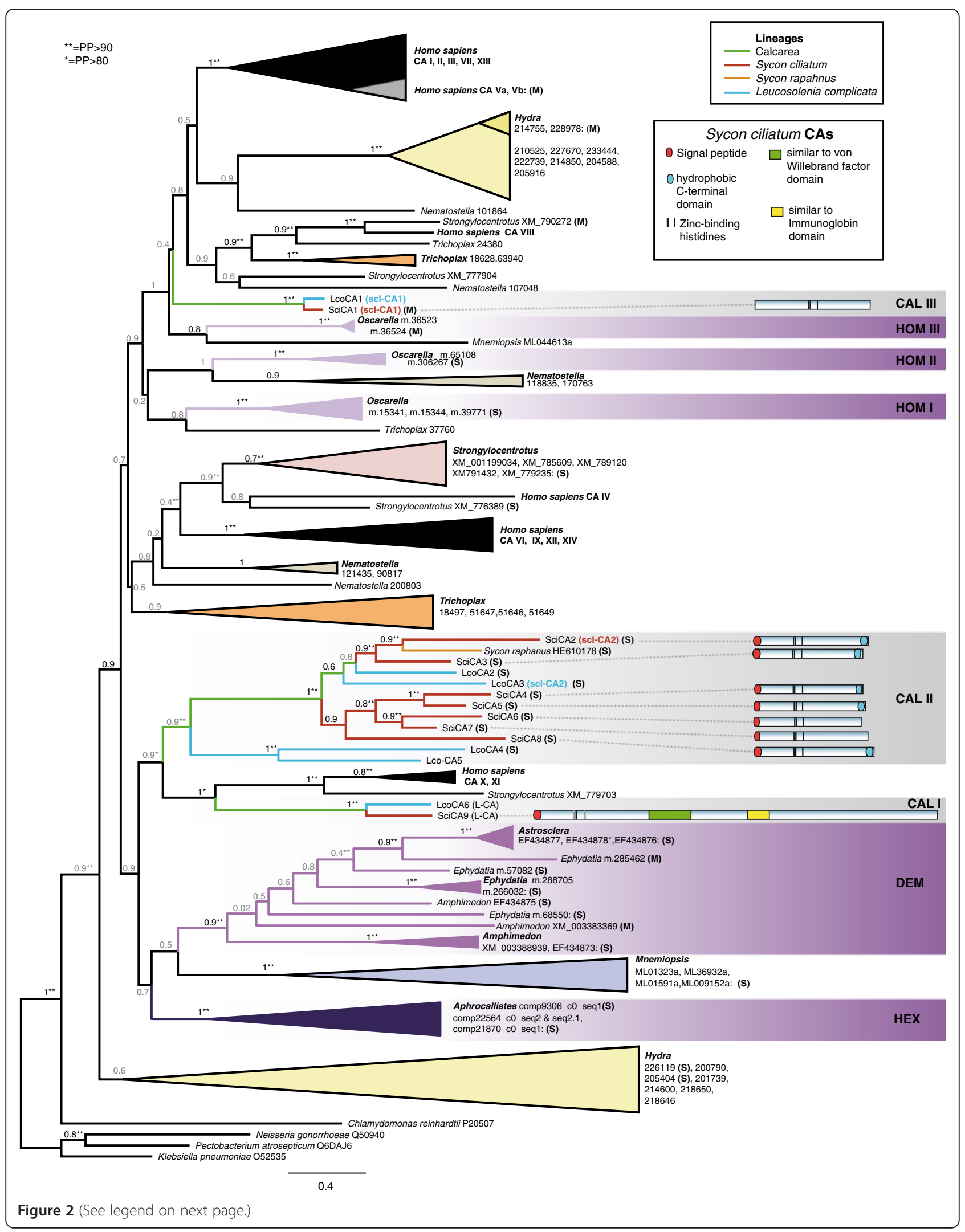


The calcarean clade CAL II contains seven S. ciliatum (SciCA2-8) and four L. complicata CAs (LcoCA2-5). With one exception from L. complicata (LcoCA5), all of these CAs have a signal peptide and, therefore, are potentially secreted. In S. ciliatum, five of these CAs additionally have a terminal hydrophobic transmembrane domain (SciCA2-5, SciCA8), which is also present in two CAs in L. complicata (LcoCA2, LcoCA3), suggesting that these CAs are possibly bound to the extracellular membranes. The remaining CAs (SciCA6, SciCA7, LcoCA4, LcoCA5), which only show the signal peptide, might be free secreted forms. SciCA4 probably lacks CA activity because two of the three zinc-binding histidines are substituted.

The calcarean clade CAL III only contains one CA of each species, SciCA1 and LcoCA1, both lacking signal peptides and terminal transmembrane helices, so the CAs are cytosolic. A mitochondrial location is predicted by TargetP [33] only for the SciCA1, although with low certainty (Table 1).

\section{In situ hybridization and RNA-Seq analyses identify two sclerocyte-specific CAs}

In situ hybridization (ISH), and RNA-Seq (in S. ciliatum) was used to localize the spatial and temporal expression of the identified CAs in the two species. Because calcareous sponges are viviparous and only fully developed larvae leave the sponge, we could study developmental stages of $S$. ciliatum present within the adult tissue (see e.g. [27]). ISH experiments on S. ciliatum included tissues with oocytes, early embryonic stages (pre- and post inversion) and almost fully developed, but not yet released, amphiblastula larvae, as well as nonreproducing larger and smaller S. ciliatum individuals. Some experiments were conducted with post-larval and juvenile stages. For $L$. complicata, only adult tissue was used in ISH experiments.

CAs with a role in spicule formation should be expressed in active sclerocytes (as already suggested by [22]), which should be most abundant in the regions of spicule formation detected in S. ciliatum in our calcein staining experiments (Figure 1e-g), and the buds of newly forming tubes in L. complicata. In both S. ciliatum and $L$. complicata, such patterns were observed in the expression of one intracellular CA (SciCA1, LcoCA1) and of one secreted/membrane-bound CA (SciCA2, LcoCA3). Additionally, the shape of expressing cells (Figure 3b-h, Additional file $4 \mathrm{a}, \mathrm{b})$ and their location in the sponge's mesohyl (Additional file 4c) identifies the expressing cells as active sclerocytes, although the calcite spicules dissolved completely in the ISH procedure. We therefore refer to these genes as sclerocyte-specific CAs (scl-CAs): scl-CA1 (SciCA1, LcoCA1) and scl-CA2 (SciCA2, LcoCA3).

To further clarify whether the two scl-CAs are expressed in the same cells, double ISH with differentially labeled probes for each gene was performed to test the relation of scl-CA2 and scl-CA1 expressing cells in S. ciliatum. SclCA2 (SciCA2) was detected most prominently in elongated sclerocytes forming the slender diactines around the osculum (Figure 3a,b,e; compare Figure 1g). In the oscular region, scl-CA1 (SciCA1) was expressed in tetractine forming sclerocytes and sclerocyte sextets of newly forming triactines (Figure 1a), and other spicules forming in the region of the radial tube initiation (compare Figure 3e, f). In the earliest stage of triactine formation, only scl-CA1 is expressed in the six sclerocytes comprising the characteristic sextet (Figure 3f, left). From the sclerocytes of growing triactines in the radial tube, founder and thickener cells can be distinguished (compare Figure 1a), and all express scl-CA1 and scl-CA2 (Figure 3f, middle). In the double ISH, the less strong Fast Red labeling of scl-CA1 expression is not completely concealed by the purple sclCA2 expression (Figure 3f, middle, top), suggesting that scl-CA1 expression in this stage is still high. Later triactine formation was not often observed, but incidental observation showed only scl-CA2 expression in the founder cells (Figure 3g).

Due to the density and position of diactines, it is much more difficult to identify sclerocytes of a single (dissolved) diactine, especially in later stages of diactine growth. However, closely associated sclerocytes in diactine-forming parts of the sponge show expression of both scl-CA1 and scl-CA2 (Figure 3f, right). In a few incidences, we also observed a differential expression of scl-CA2 and scl-CA1 in the later founder cell and later thickener cell, respectively, in a stage that seems to be a very early diactine formation (Figure 3h), but it remains uncertain if this represents a general transitional stage in all forming diactines.

Illumina RNA sequencing (RNA-Seq) data confirms our ISH observations. It shows that in S. ciliatum the scl-CAs are, overall, continuously expressed in high levels and are significantly higher expressed in the top of the sponge compared to the middle or bottom part (Figure 2, see also [28]). Expression levels of the two genes are also highly correlated $\left(R^{2}=0.93\right)$. Furthermore, expression in spicule free stages was detected by RNA- 


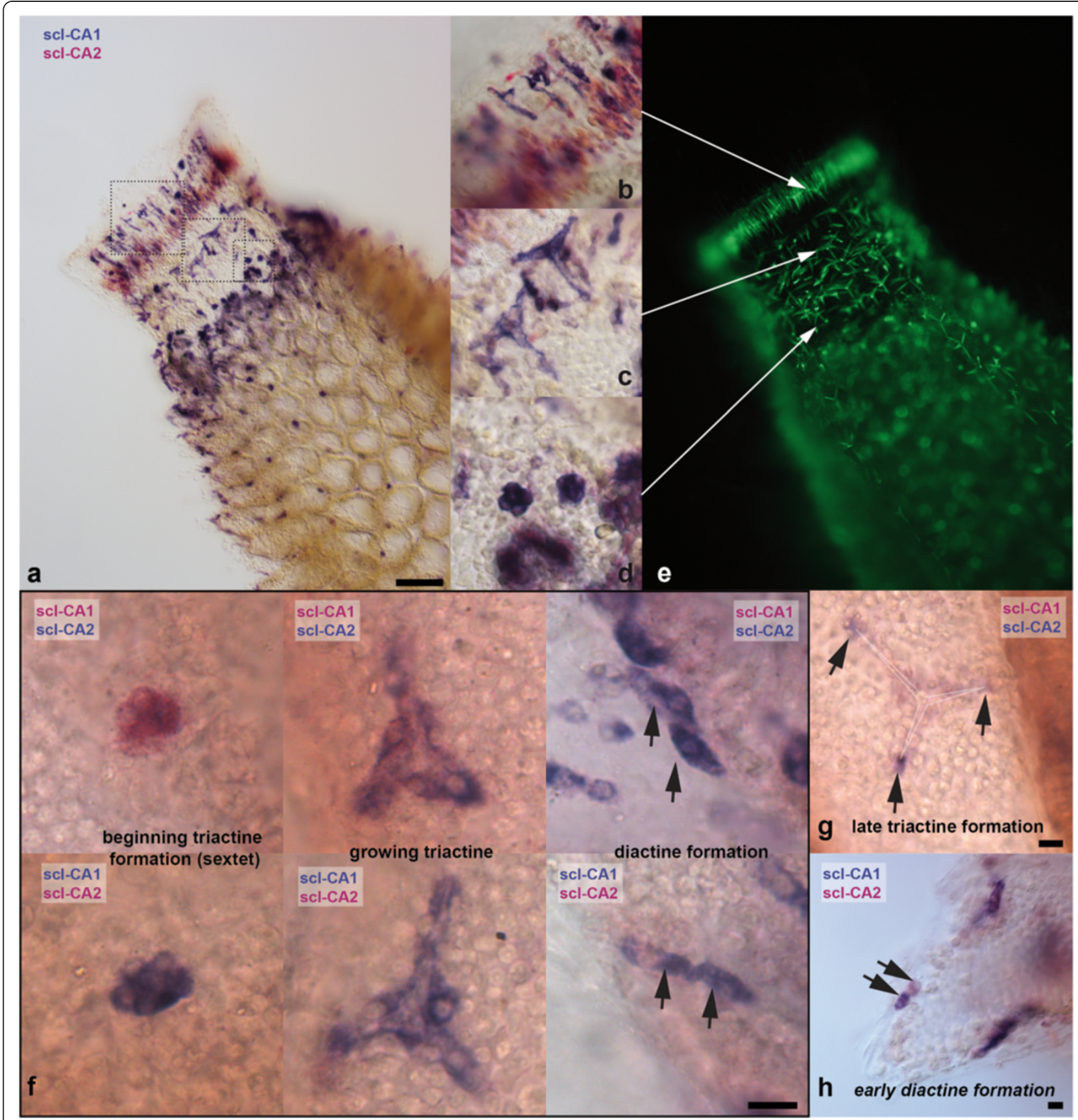

Figure 3 Spicule formation patterns and expression patterns of scl-CA1 and scl-CA2 in S. ciliatum. (a-d, f-h): double ISH with differentially labeled probes. (a-e) small S. ciliatum individual, longitudinally cut and viewed from atrial side (scale bar: 100 um). (b, c, d) Details from boxed areas in a. (b) Predominant scl-CA2 expression in elongated, diactine-forming sclerocytes. Note scl-CA1 expression in presumably tetractine-formation and in some elongated sclerocytes (compare to (e)). (c) scl-CA1 expression in tetractine forming sclerocytes. (d) scl-CA1 expression in sextets of sclerocyte cells, presumably early triactine formation of initial radial tubes. (e) Calcein staining showing spicule growth of $18 \mathrm{~h}$. (f-h) Expression of scl-CA1 and scl-CA2 in sclerocytes of spicule formation in the radial tubes (scale bars: 100 um). (g) scl-CA2 expression (purple) in founder cells. (h) Incidentally observed expression of scl-CA1 and scl-CA2 in two sclerocytes (presumably beginning diactine formation).

Seq (larvae, settled postarval stage i, Figure 4a). ISH with larvae revealed weak expression in a ring of posteriormost micromeres (Additional file 4d, e). Micromeres make up the internal cell population of just settled larvae (postlarvae stage i), which still lack spicules but already highly express scl-CAs (Figure 4a). The first spicules to form are diactines, the only spicule type in postlarval stages ii-iii (Figure 4b). Here, the expression of scl-CAs is highest of all observed stages. In later stages, first triactines appear (iv-v, Figure $4 \mathrm{~b}$ ); then, after 


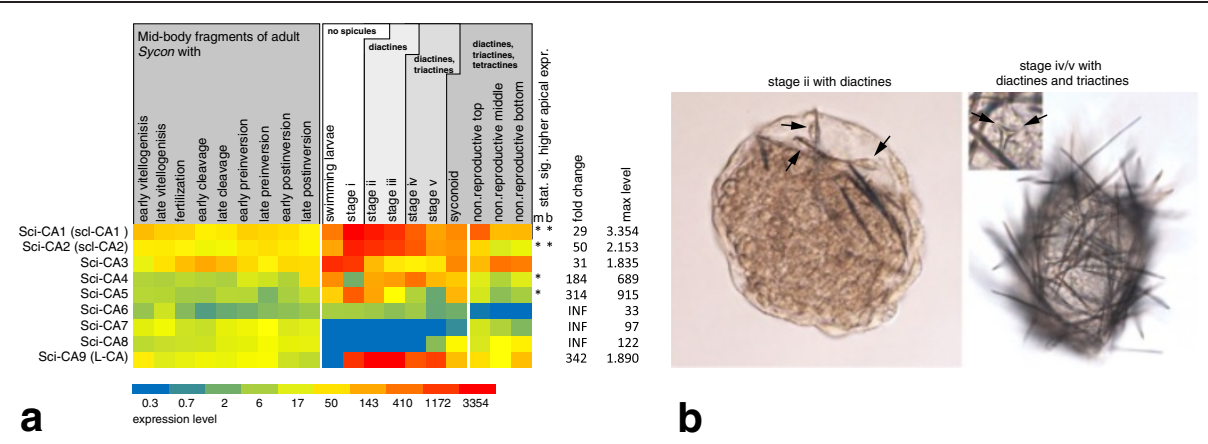

Figure 4 Expression of CAs in different tissues and stages, juvenile stages. (a) Heatmap representation of RNA-Seq expression profiles of CAs in different developmental stages and body parts of $S$. ciliatum. Expression level for each gene and stage or body part was calculated as a sum of the posterior probability of each read coming from that gene over all reads [36] and adjusted with size factors of the RNASeq libraries [37]. Statistically significant higher expression in the apical (top) region of the non-reproductive sponges in comparison to the middle or basal part is indicated by asterisks (' $m$ ' in comparison to the middle, ' $b$ ' in comparison to the base). The statistical significance was assessed using the adjusted $p$-value from DESeq package ( $p$-value adjusted for multiple testing), padj $\leq 0.1$.RNA-Seq. (b) Postlarval stages of $S$. ciliatum with only diactine (left) and diactine and triactine spicules (right). Arrows point at sclerocytes.

opening of the osculum and change of the juvenile morphology from round to vase-shaped, slender diactines form around the osculum (stage v). Tetractines were not observed (but were not specifically searched for) in juveniles, but were previously reported to appear first around the newly formed osculum [35], and in the later stages are present around the atrial cavity.

\section{Localization and expression of other CAs}

According to RNA-Seq analysis, several CAs had low expression levels or no expression in studied stages, and we did not observe any expression pattern by RNA ISH in the studied stages of the sponge (SciCA5, SciCA6, SciCA8, Figure 4a). Because the active spicule formation detected by the calcein staining experiments requires the activity of CAs [22], we assume that the low-level expressed CAs are unlikely to be involved in the process. Expression of the presumably acatalytic L-CA SciCA9 (see above) peaks in post-settlement stages i-v, but was low in adult sponges (Figure 4a), where no ISH pattern could be observed. Because of the putative lack of CA activity (see above) and the fact that in spicule-forming adults expression is low, an involvement of this protein in biomineralization cannot be assumed.

Other CAs exhibited expression patterns with no relation to spicule forming sclerocytes (Additional file 4f-h). Besides the scl-CAs, SciCA3 also showed the highest expression levels in adult sponges. Here, the expression peaks in sponges with oocytes and early embryos (Figure 4), in which the transcripts of SciCA3 could be localized with ISH (Additional file 4f). We have not detected any cell-specific SciCA3 expression in the adult tissues and larvae, although RNA-Seq analysis indicates the presence of transcripts. Instead, choanocytes and, to a lower extent, pinacocytes, as well as all larval cells, developed uniform staining after a prolonged color reaction (Additional file 4f), consistent with the low-level ubiquitous expression of this gene, although qualitatively this staining is undistinguishable from background. A similar weak ubiquitous signal was observed for LcoCA2, while no expression patterns were detected for all the other LcoCAs except the scl-CAs in adult $L$. complicata sponges. SciCA7 expression was seen in exopinacocytes at the proximal base of the radial tubes of some adult sponges (Additional file 4g), but expression levels according to RNA-Seq were generally low in adult sponges (Figure 4a). ISH showed localized expression of SciCA4 in the macromeres of the larvae (Additional file 4h). Finally, SciCA9 (L-CA) was highly expressed only in juvenile stages i-v according to RNA-Seq (Figure 4i). The results of the iSH and RNA-Seq experiments are summarized in Table 2.

\section{Phylogenetic analysis}

We reconstructed the relationship of CAs from sequenced genomes of all non-bilaterian phyla and additional transcriptomes of all four sponge classes (Additional file 5) with Maximum Likelihood (ML) and Bayesian methods to gain insight into the enzyme's evolutionary history.

We did not recover a strictly eumetazoan CA clade as a sister group to demosponge CAs, which had been the result of earlier studies with fewer taxa [3,11,14,25]. Although approximate likelihood ratio test (aLRT) support values are high, bootstrap support is low, especially in the deeper nodes (Figure 2). The Bayesian phylogeny (Additional file 6) reflects these uncertainties by the presence of polytomies. Furthermore, some relationships differ from the ML topology, but mostly these alterative branchings are not highly supported. For example, in ML, a clade of Hydra CAs constitutes the sister group to 
Table 2 CA expression patterns of CAs in S. ciliatum

\begin{tabular}{lll}
\hline CA & ISH & RNA-Seq \\
\hline SciCA1 (scl-CA1) & $\begin{array}{l}\text { Sclerocytes, weak signal in ring of posterior-most micromeres } \\
\text { in larvae }\end{array}$ & $\begin{array}{l}\text { All stages (including spicule-free larva and postlarval stage i), } \\
\text { higher expression in top region of sponge }\end{array}$ \\
SciCA2 (scl-CA2) & $\begin{array}{l}\text { Sclerocytes, weak signal in ring of posterior-most micromeres } \\
\text { in larvae }\end{array}$ & $\begin{array}{l}\text { All stages (including spicule-free larva and postlarval stage i), } \\
\text { higher expression in top region of sponge }\end{array}$ \\
SciCA3 & $\begin{array}{l}\text { Elevated expression in oocytes and early embryos; ubiquitous } \\
\text { expression in other cell types including all larval cells. }\end{array}$ & $\begin{array}{l}\text { All stages, higher expression in sponges with oocytes and early } \\
\text { embryos, larvae and postlarval stage i }\end{array}$ \\
SciCA4 & Larval macromeres & $\begin{array}{l}\text { In larvae and postlarval stages ii-v, low expression in adult sponges } \\
\text { SciCA5 }\end{array}$ \\
Undetected & Undetected & $\begin{array}{l}\text { Higher in larvae, postlarval stages i-iii, young syconoid sponge, } \\
\text { low in other stages and adult sponges }\end{array}$ \\
SciCA6 & Proximal exopinacocytes between radial tubes & $\begin{array}{l}\text { Very low expression during embryonic and postembryonic } \\
\text { development }\end{array}$ \\
SciCA7 & Undetected & $\begin{array}{l}\text { Low expression in adult sponges } \\
\text { Low expression in adult sponges }\end{array}$ \\
SciCA8 & Undetected & $\begin{array}{l}\text { Highly expressed in postlarval-juvenile stages i-v, low } \\
\text { expression otherwise }\end{array}$ \\
\hline
\end{tabular}

all remaining CAs, while in the Bayesian tree (Additional file 6) we observe a polytomy at the base of Metazoa, with some of the mentioned Hydra CAs nested elsewhere in the tree. Most of the shallower clades occur in both trees, but in different relationship to each other, including the sponge clades. Further discussion will focus on the ML tree (Figure 2) because the model $(L G+G)$ proposed by ProtTest 3 [38] was not available in MrBayes [39], which might in part be the reason for the discrepancies. Long branch artifacts could also influence our phylogenies (see e.g. [40]). Despite these difficulties and incongruences, the following important conclusions can be drawn from our phylogenetic analyses.

Sponge CAs are much more diverse than anticipated from previously reported demosponge CA sequences and, in our phylogenies, are not recovered in a single clade. Instead, demosponge CAs are a sister group to some ctenophore CAs, which together form the sister group to hexactinellid CAs (but compare the Bayesian phylogeny, in which a weakly supported monophyletic clade of CAs from these sponge classes is recovered, Additional file 6). However, CAs of both sponge classes are monophyletic. In contrast, the CAs of calcareous sponges and homoscleromorph sponges are more diverse, and three CA clades with no close relation to each other can be found in both classes (CAI-III and HOM IIII, respectively). Each of the three calcarean CA clades contains sequences from S. ciliatum and L. complicata. In clades CAL I and CAL III, only one CA gene of each species is included, with additional evidence of evolutionary conservation: scl-CA1 (clade CAL III) display sclerocyte-specific expression, while CAs of clade CAL I are characterized by the additional $\mathrm{C}$-terminal domain (see above), and form a sister clade to the human CARPs CA X and CA XI and a sea urchin CARP (XP_779703).
In contrast, relationships in clade CAL II are more complicated: Scl-CA2 of S. ciliatum and L. complicata both occur in this clade, but are not the closest related CAs. Instead, S. ciliatum scl-CA2 and the Sycon raphanus CA form a clade, to which SciCA3 is the sister group. Still closer than the L. complicata scl-CA2 (LcoCA3) is yet another L. complicata (LcoCA2, but see the Additional file 6 for a slightly alternative topology in the Bayesian phylogeny). This pattern demonstrates the difficulties in inferring CA function from only phylogenetic reconstructions, and suggests gene duplications and losses since the last common ancestor of the two species. From the phylogenies, it is obvious that scl-CA1 and scl-CA2 are not closely related and, therefore, most likely have been recruited independently in the biomineralization process. Neither scl-CA1s nor sclCA2s have phylogenetic affinities with the Astrosclera CAs, which have been shown to be involved in the formation of the basal carbonate skeleton of this demosponge species [3].

With the exceptions of Demospongiae and Hexactinellida, all included taxa possess more than one clade of CA, which must have arisen by CA duplications in early animal evolution. Also, species-specific or group-specific clades of CAs occur for all included taxa, suggesting a very frequent lineage-specific diversification of CA genes in animals. To gain further insight in CA evolution, we reconciled our CA phylogeny with two more recent hypotheses $[41,42]$ and a more classical hypothesis about the relationships of non-bilaterian animals with methods provided in Jane 4 [43]. For each of the three phylogenetic hypotheses we visualized the potential CA gene histories, and found that in all cases frequent duplications and losses of CA genes can be observed (Figure 5a and Additional file 7). The reconstructions suggest that 


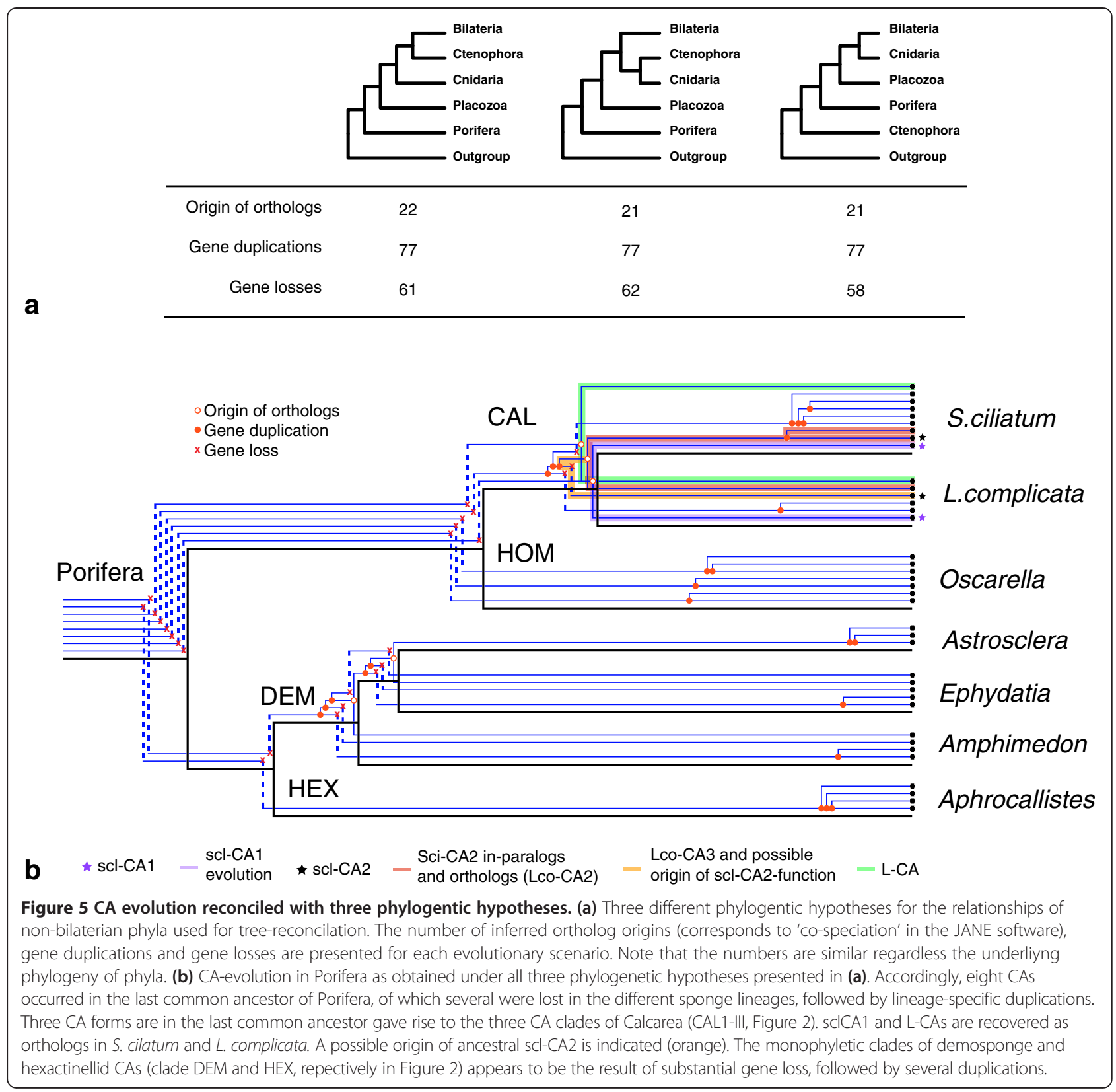

the last common ancestor of metazoans already possessed multiple CA genes, but the number of genes differs between the phylogenetic hypotheses (Additional file 7). Despite the underlying phyla-phylogeny, the presence of eight CAs in the common ancestor of sponges is reconstructed and identical gene histories within sponges are observed (Figure $5 \mathrm{~b}$ ). In each sponge class different ancestral CAs were lost, followed by a radiation from the remaining $\mathrm{CA}(\mathrm{s})$. At least three versions of $\mathrm{CAs}$ were present in the common ancestor of Calcarea, which were ancestral to L-CAs, scl-CA1 and to the CAs of clade CAL II, respectively. Clade CAL II includes scl-CA2, but within this gene lineage duplications and losses occurred after the common ancestor of S. ciliatum and L. complicata (Figure 5), which complicates ortholog assignment. According to our phylogenetic analyses and the tree reconciliation, scl-CA2 of S. ciliatum (SciCA2) and $L$. complicata (LcoCA3) are not of ortholog origin but instead might be out-paralogs, originating from a gene duplication that predated the speciation event (Figure $5 \mathrm{~b}$ ). The low support values and the differing topology of the Bayesian analyses, however, make unambiguous interpretations difficult. S. ciliatum scl-CA2 (SciCA2) and SciCA3 are in-paralogs, diverging from a lineage-specific duplication of an ancestral gene, and both are co-orthologs to LcoCA2 (Figure 5). 


\section{Discussion}

\section{Correlations and differences in scl-CA1 and scl-CA2 expression}

Jones and Ledger [22] considered the possibility that the biomineralizing calcarean CA is cytoplasmic or secreted/ membrane-bound. We present evidence that indeed two forms, one cytosolic and potentially mitochondrial form (scl-CA1) and one secreted/membrane-bound form (sclCA2), are involved in spicule formation. The expression of both scl-CAs is highly correlated, and both scl-CAs are simultaneously expressed in triactine and diactine forming sclerocytes (Figure 3), suggesting a close interplay of the proteins in biomineralization. However, expression of the intercellular scl-CA1 precedes the initiation of secreted and membrane-bound scl-CA2, at least at the onset of triactine-formation in the sextet of sclerocytes (Figure 3f), but this stage might be very short-lived and obviously does not influence the strong correlation of the expression of the scl-CAs in the RNA-Seq data. It remains to be tested if, at this point of spicule formation, carbonate deposition has not yet started and if the presence of the extracellular scl-CA2 is required for its initialization. In late stages of spicule formation, expression of sclCA2 was only observed in founder cells (Figure $3 \mathrm{~g}$ ), which at this stage are no longer in physical contact to the thickener cells (Figure 1a).

Additionally, we observed a predominant scl-CA2 expression in the slender diactine forming sclerocytes situated around the osculum (however, some of these cells also showed scl-CA1 expression). It is noteworthy that the slender diactines are the fastest growing spicules in the sponge, as we found from the calcein staining experiments (Figure 1d). Furthermore, the texture of slender diactines of Sycon was reported to be almost identical to that of synthetic calcite and it was proposed that they contain no protein, in contrast to the other spicule types of the sponge [44]. If no additional proteins need be secreted to form slender oscular diactines, this may allow for faster growth, which can be driven by higher sclCA2 expression levels in these sclerocytes.

\section{The role of the carbon source in understanding scl-CA function}

The catalytic function of CAs (the interconversion of $\mathrm{CO}_{2}$ to $\mathrm{HCO}_{3}{ }^{-}$) can be involved in carbonate formation in animal skeletons in different ways, and is also dependent on the carbon source -metabolic $\mathrm{CO}_{2}$ or dissolved inorganic carbon (DIC) from the seawater- of the formed carbonate $[16,45]$. In corals, the origin of the carbonate carbon source is still debated and probably differs between species [11]. Consequently, the role of CAs in coral biomineralization is also not completely resolved. Secreted/membrane-bound CAs located at the calcification site can contribute to biomineralization in two ways, as, for example, was considered for a membrane-bound $\mathrm{CA}$ in the azooxanthellate coral Tubastrea aurea. If in the first case the skeleton's carbon is largely of metabolic origin, activity of this CA can provide $\mathrm{HCO}_{3}{ }^{-}$for the formation of $\mathrm{CO}_{3}{ }^{2-}$ : in the presence of calcium, the produced $\mathrm{CO}_{3}{ }^{2-}$ can precipitate as calcium carbonate [16]. Alternatively, the authors argued that if $\mathrm{HCO}_{3}{ }^{-}$(DIC) from seawater was the main carbon source of carbonate in Tubastrea, the extracellular CA could eliminate the protons that are released by the conversion of $\mathrm{HCO}_{3}{ }^{-}$to carbonate. In this case this CA would catalyse the reaction of a proton and $\mathrm{HCO}_{3}{ }^{-}$ ion to $\mathrm{H}_{2} \mathrm{O}$ and $\mathrm{CO}_{2}$ [16].

As in corals, the carbon source of the calcareous sponge spicules is unknown. When the $\mathrm{HCO}_{3}{ }^{-}$-concentration of seawater is artificially lowered below a certain threshold, no spicules are formed; this could be due to the fact that the amount of metabolic $\mathrm{CO}_{2}$ alone is not sufficient to maintain spicule formation [35]. However, under the conditions applied in this study, the lowering of the bicarbonate concentration in artificial seawater simultaneously led to acidification, which also may be the reason for of the lack of spicule formation [35]. Additional information about the carbon source of spicules can be drawn from stable isotope analyses of calcareous sponge spicules from species collected at the Great Barrier Reef [46]. In those samples, the $\delta^{13} \mathrm{C}$-values differed among species, and were consistent with the separation of the two calcareous sponge subclasses. This observation contradicts the assumption that seawater is the sole carbon source because in this case similar values for specimens from the same environment would be expected. In fact, differences in the contribution of metabolic carbon and DIC to skeleton formation of different species might be the cause of the observed pattern. Therefore, we assume that metabolic $\mathrm{CO}_{2}$ contributes considerably to the carbon source of calcitic spicules in Calcarea.

\section{Potential function of scl-CA1 and scl-CA2 in biomineralization}

We have two scenarios for a potential interplay of sclCA1 and scl-CA2 (Figure 6), which differ in the role of the secreted/membrane-bound scl-CA2. In both scenarios, the intracellular scl-CA1 transforms metabolic $\mathrm{CO}_{2}$ to $\mathrm{HCO}_{3}{ }^{-}$within the sclerocyte, which then is secreted to the extracellular spicule formation site by a bicarbonate transporter [47]. The metabolic $\mathrm{CO}_{2}$ may not only be produced by mitochondria within the sclerocyte, but also by pinacocytes, choanocytes and other cells of the mesohyl, and diffuse into the sclerocyte. It is then possible that scl-CA2 at the calcification site transforms excess $\mathrm{CO}_{2}$ into additional $\mathrm{HCO}_{3}{ }^{-}$, which diffuses from the sclerocyte (Figure 6, left). In this case protons from the formation of carbonate could be actively removed, 


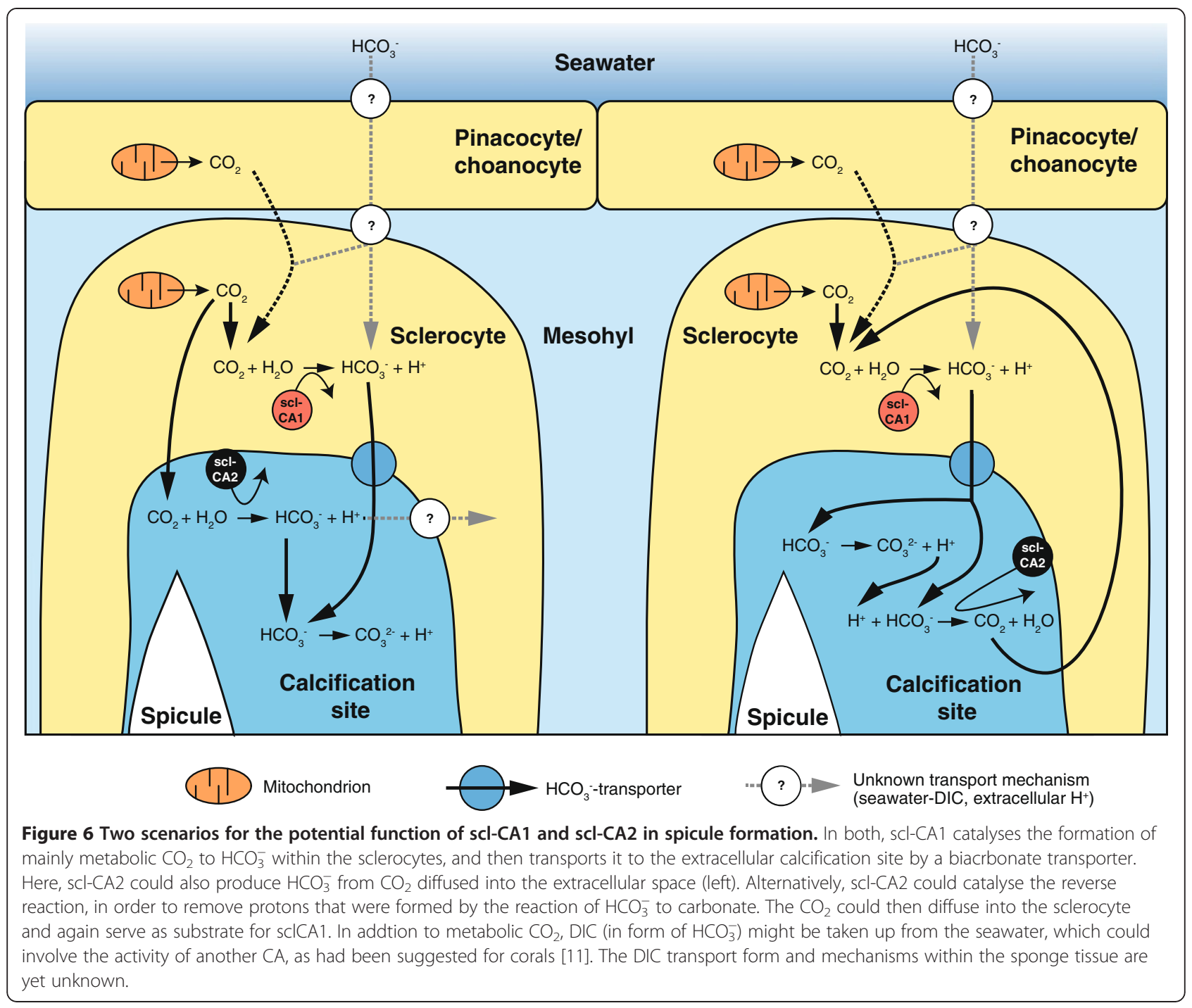

e.g. by a yet unknown $\mathrm{Ca}^{2+}$-ATPase, which in turn delivers $\mathrm{Ca}^{2+}$ to the calcification site, as has been proposed for corals $[16,48]$. Alternatively, the function of scl-CA2 could be to eliminate the protons by catalyzing the reaction of two $\mathrm{HCO}_{3}{ }^{-}$-ions and one proton to produce $\mathrm{CO}_{2}$ and $\mathrm{H}_{2} \mathrm{O}$ (Figure 6 , right). The $\mathrm{CO}_{2}$ in turn could diffuse into the sclerocyte and serve as substrate for scl-CA1. This function of secreted/membrane-bound CAs was proposed for corals, if DIC in the form of $\mathrm{HCO}_{3}{ }^{-}$was the main carbon source for the skeleton $[11,16]$. This is not a prerequisite in calcareous sponges as $\mathrm{HCO}_{3}{ }^{-}$could also be provided by the activity of scl-CA1. However, DIC taken up by choanocytes or pinacocytes from seawater may contribute to the carbon pool, regardless of the function of scl-CA2, but neither the uptake mechanism nor the form of transportation is known. In corals, a membrane-bound CA from ectodermal cells is believed to be involved in DIC uptake by transforming $\mathrm{HCO}_{3}^{-}$ into $\mathrm{CO}_{2}$, which diffuses into the cell [11]. According to the expression profiles, the only calcarean CA that showed continuous and high expression as would be expected for an enzyme with such a critical role is SciCA3, the closest CA to scl-CA2. The expression pattern of this gene appeared ubiquitous in adult tissues but elevated in oocytes and early embryos (see Additional file 4f), consistent with involvement of this CA in DIC uptake, where expression in choanocytes and pinacocytes would be expected.

\section{Evolution of CAs in sponges}

To our knowledge, the phylogenetic analyses presented here is the first that includes CAs found in the completely sequenced genomes of all non-bilaterian phyla. Our phylogenetic trees strongly suggest that the CA repertoire of non-bilaterians, and especially sponges, is much more diverse than previously suggested by analyses that only included demosponge sequences. The last common ancestor of Metazoa is predicted to have 
already possessed a number of CAs (Additional file 7), instead of a single ancestral CA as had been suggested [3]. In contrast to this previous study, our results also suggest that the ancestor of sponges possessed a rich CA-repertoire (eight predicted ancestral CAs), of which several CAs were lost in the independent lineages that lead to the four recognized sponge classes. The extant CA-diversity in demosponges and hexactinellids is due to a reduction with a subsequent radiation of only a single ancestral CA lineage in both classes (Figure 5). The evolution of CAs in Metazoa was clearly driven by frequent gene diversification and gene loss events (Figure 5 and Additional file 7). This highly dynamic evolution makes CAs eligible for repeated independent recruitment in novel physiological roles, such as biomineralization, in different metazoan lineages, as we now also established for Calcarea. Even within calcareous sponges, duplications (and losses) occurred and, from all studied sponges the highest diversity of CAs was found in $S$. ciliatum. We could infer at least three hypothetical ancestral forms of CAs (one ancestral form for each calcareous sponge CA clade) in the last common ancestor of calcareous sponges from our phylogeny (Figure 2) and tree reconciliation (Figure 5): one intracellular form (ancestral to scl-CA1), one secreted or membrane-bound form (ancestral to scl-CA2 and related CAs), and one secreted form with $\mathrm{C}$-terminal domains of unknown function (ancestral to L-CAs). The CA-domain of the latter is closely related to the two human CARPs, CA X and CAXI. The function of mammalian CARPs is unknown, but they are expressed predominantly in brain tissue and the binding of other proteins was suggested as a novel function of CARPs $[10,12]$. Interestingly, human CARPs CA X and CA XI, the potential urchin CARP and the CA-domain of L-CAs share specific amino acid substitutions in four to five positions that are conserved active sites of catalytic CAs [9]. The substitutions may be related to the altered functions of these proteins. CARPs related to human CAX and CAXI were previously known from other bilaterians [12], and the proposed close relationship of cnidarian CAs (Nematostella_107048 in Figure 2) to human CA X and CA XI [11] was not recovered in our tree. With our findings of L-CAs in calcareous sponges, it seems that these acatalytic CARPs (CA X, CA XI) have a much older origin at the base of metazoans.

The clade CAL II, which includes scl-CA2 (SciCA2 and LcoCA3) of both studied species, is the most diverse of the calcareous CA clades and gene orthology cannot be assessed easily due to duplications and losses (Figure 5). We found that SciCA2 and LcoCA3 are isofunctional paralogs involved in spicule formation. SciCA2 and SciCA3 are co-orthologs to LcoCA2, which originated from a lineage-specific duplication event after the separation of from L. complicata and S. ciliatum. According to our expression analyses, a functional differentiation of the two co-orthologs also occurred. The shared ancestral origin of the scl-CA2 genes is a gene duplication that predated the separation of the two species (Figure 5). Given the variety of temporal and spatial expression observed in S. ciliatum CAs of clade CAL II (SciCA2-8) the question remains as to what the function of the ancestral CA could have been. In our view, the independent recruitment of SciCA2 and LcoCA 3 and CAs for biomineralization is very unlikely because of the similarities in the processes reported from both species $[18,19]$ and the fact that their last common ancestor already must have processed calcite spicules (compare calcarean phylogeny in [49]). Conclusively, the involvement in biomineralization must be considered a plesiomorphic function of the CAs of this clade. The data, therefore, provides evidence that the last common ancestor of the calcareous sponges possessed two sclerocyte-specific CAs (Figure 5), which together are fundamental parts of the biomineralization toolkit in calcareous sponges. No pair of these intra- and extracellular scl-CAs are closely related to CAs involved in formation of the carbonate basal skeletons of the demosponge Astrosclera [3], supporting the view that CA-mediated carbonate formation evolved independently in calcite-spicule forming Calcarea and demosponges with a basal carbonate skeleton. The interaction of the two calcarean scl-CAs has to be considered as an evolutionary novelty that triggered the radiation of the extant calcareous sponges.

The increased taxon sampling, compared to previous studies of metazoan CA relationships (e.g. [3,11,14,25]), revealed that the deeper nodes are especially difficult to resolve. Our analyses lack strong BS and PP support in many nodes. Support as measured by aLRT values was in many cases higher and seemed to provide overoptimistic estimations in our tree reconstructions, especially for nodes with only low BS or PP support. aLRT have been shown to provide overoptimistic support values for data sets with a weak phylogenetic signal [50]. Therefore, phylogenetic analyses that only rely on SH-like aLRT values as measure of support (e.g. [25]) should be interpreted with caution if a weak phylogenetic signal is expected, as in the analyses of CAs. One has to consider that the resolution of nodes that, according to our results, date back to the origins and radiation of Metazoa. Reconstructing a supported phylogeny of such old evolutionary events is most unlikely when genomic and phylogenomic approaches utilizing hundreds of genes fail to provide a clear phylogenetic hypotheses about the relationships of the basal animal phyla (e.g., [40]).

\section{Relations of scl-CAs to Sycon raphanus CA}

One of our identified scl-CAs in S. ciliatum, scl-CA2, is most similar to the only CA so far reported from calcareous sponges, Sycon raphanus CA [23,24], and likewise shares a 
signal peptide and a potential terminal transmembrane helix of the clade CAL II (Figure 2). A role in both spicule dissolution under $\mathrm{Ca}^{2+}$-depletion and coordinated spicule growth in in-vitro experiments has been suggested for the $S$. raphanus CA $[23,24]$. However, the authors showed an almost pervasive presence of the $S$. raphanus CA protein in many different cell types, including choanocytes (Figure 2C in [23]), similar to SciCA3 but not any other CA we have tested. Interestingly, S. raphanus CA is also detected in macromeres of an amphiblastula larva, coincidentally shown in one of the presented sections (Figure $2 \mathrm{C}$ in [24]), and is thus reminiscent of macromere-specific expression for SciCA4 (Additional file 4h), but not of sclCA2 (Additional file 4e). Without knowing how many CAs are present in S. raphanus, it is difficult to say whether one S. raphanus CA is expressed in a combination of patterns from SciCA3 and SciCA4 or if the antibody is detecting several CAs simultaneously. In either case, in contrast to $S$. ciliatum and L. complicata scl-CA2 genes, the described $S$. raphanus CA gene expression does not appear to be sclerocyte-specific. Bearing in mind the surprisingly high diversity of calcareous sponge CAs demonstrated in the current study, especially within clade CAL II, and the fact that the genus Sycon is polyphyletic with $S$. ciliatum and S. raphanus not closely related [51,52], further studies should confirm the proposed function and localization of the S. raphanus CA for spicule formation.

\section{Conclusion}

We identified one intracellular (scl-CA1) and one extracellular (scl-CA2) sclerocyte-specific CA as key components in biomineralization process of calcareous sponges. These enzymes are part of a complex repertoire of CAs in this sponge class. They differ fundamentally from the hitherto known sponge CAs from the class Demospongiae, for example by including acatalytic forms related to human CARPs CA X and CA XI. We demonstrate that the evolution of this enzyme family is very complex, both in terms of protein sequence and regulation of expression. Gene duplications apparently involved functional diversification with consequent differentiation in expression patterns. We propose that involvement in biomineralization was the original function of an ancestral enzyme of clade CAL II CAs that by gene duplication and functional diversification gave rise to the majority of the secreted/membranebound calcarean CAs with differing functions. Detailed expression studies, rather than sequence comparison alone, have proven most valuable in inferring the involvement of a specific CA in spicule formation, and the two identified genes can now serve as markers of active sclerocytes. Like corals and other calcifying marine invertebrates, calcareous sponges are potentially highly impacted by ocean acidification due to raising atmospheric $\mathrm{CO}_{2}$ levels [53]. Understanding the molecular processes in calcareous sponge biomineralization can help to estimate if or how Calcarea might respond to the changing environment.

\section{Methods}

\section{Sequence identification and analysis}

Genomic and transcriptomic sequences and RNA-Seq data were obtained as described previously [27-29]. CAs were identified using BLAST [54]. Sequences with $>99 \%$ similarity were considered as allelic variants or splicing variants (Table 1 ).

The server versions of SignalP 4.0 [31], TargetP 1.1 [33] (both available at: [55]) were used to detect potential signal peptides and predicted subcellular location of CAs. Transmembrane domains were predicted with TMHMM-2.0 [32].

Amino acid sequences of CAs from additional taxa were obtained from GenBank [56] or identified by BLAST searches against data from sequenced invertebrate genomes [42,57-63] and transcriptomes [64] from data of publicly available sources: Compagen $[65,66]$ and Metazome v3.0 [67] (Additional file 5). In Hydra, we excluded some proteins, which had additional domains and only partial CA-domains. Sequences were aligned with MAFFT version 7 [68] and sites for phylogeny were chosen manually by selecting regions of likely homology between conserved sites identified with Gblocks [69] (Additional file 8). ProtTest 3 [38] proposed the use of the $\mathrm{LG}+\mathrm{G}$ model for maximum likelihood analysis (ML) under the AIC criterion. ML phylogenetic analysis was performed with PHYML [50], including 200 bootstrap replicates and SH-like aLRT to obtain support values. Bayesian inference was performed with MrBayes [39], using the mixed amino-acid model (because LG is not available), with a gamma parameter to account for rate heterogeneity. Two MCMCMC runs, with 4 chains each, were run for 10 million generations; every $1000^{\text {th }}$ tree was sampled. We omitted the first $40 \%$ of the sampled trees for the calculation of the consensus tree shown in Additional file 6 . Tree reconciliation was performed in Jane 4 [43], using a simplified version of our ML phylogeny as "parasite" and different hypotheses [41,42] about phylum relationships as "host" tree. Sponge class and family relationships correspond to these and previous results [70]. In Jane 4 we used a population size of 2.000 for 200 generations with the 'host switch' parameter turned off.

\section{Sampling and calcein disodium staining}

Specimens of S. ciliatum and L. complicata were collected and fixed for ISH as described previously [27]. For calcein staining, living specimens were transferred to a petri dish containing $30 \mathrm{ml}$ of calcein disodium solution $(12.5$ or $125 \mathrm{mg} / \mathrm{ml}$, Fluka) in seawater, and incubated at $14^{\circ} \mathrm{C}$ for $3-24 \mathrm{~h}$. After cleaning by rinsing the 
treated sponges two times with fresh seawater, sponges were observed under fluorescence microscope (Nikon AZ100, using EGFP filter 41017) or fixed in 70\% ethanol for later use. Carbonate deposited on the spicules during the incubation showed fluorescence due to the incorporated calcein. Spicules of sponges treated $18 \mathrm{~h}$ in calcein were isolated using bleach solution (containing $4 \%$ sodium hypochlorite), washed five times with deionized water and mounted on a microscopic slide. Two sponges were embedded in resin and sectioned with a Leica 1600 saw microtome as described previously [49]. Spicule growth was measured on spicule preparations (Figure 1b) for curved diactines and triactines. Growth of the more fragile slender diactines was measured in longitudinal sections (Figure 1c) because the spicules were easier to detect and remained undamaged. Spicule growth was measured in sponges incubated for $18 \mathrm{~h}$ at $14^{\circ} \mathrm{C}$, which was preferred over a shorter $3 \mathrm{~h}$ incubation because the fluorescent spicules were very sparse in spicule preparations. To exclude spicules that began their formation long after the incubation had started, small completely fluorescent spicules were ignored. Incubations of $24 \mathrm{~h}$ were avoided so as to exclude measurement of spicules that stopped growing during the incubation. However, the possibility that some spicule elongation ceased before the end of the $18 \mathrm{~h}$ incubation cannot be excluded. Due to these considerations, the values presented in Figure 1d may underestimate the actual spicule growth rate.

\section{RNA in situ hybridization (ISH)}

DIG-labeled specific antisense RNA probes were generated from $700-830 \mathrm{bp}$ of the coding regions of all identified CAs of S. ciliatum CAs and of L. complicata from pooled cDNA from different developmental stages. PCR primers sequences are provided in Additional file 9. PCR products were cloned into the PCR4-vector (Invitrogen) and sequenced to determine the insert orientation. An additional PCR with the corresponding reverse vector primer and a probe-specific forward primer provided the template for the synthesis of DIG-labeled RNA probes (Dig-labeling kit, Roche). The probes were used in ISH of fixed tissue as described previously [27-29]. Fixed tissues included freshly fixed small $S$. ciliatum specimens and previously fixed larger sponges, some containing different developmental stages (oocytes, cleavage stages, pre- and post-inversion embryos and pre- release larvae). For ISH with L. complicata, only adult tissue was used and was treated in the same manner. During the ISH protocol, the carbonate spicules dissolved completely in most specimens. Double ISH was performed to compare expression of two selected genes in the same tissue by combining digoxigenin (DIG) and fluorescein labeled antisense probes of target genes. Gene expression was visualized by application of antibodies (FAB-anti-DIG and FAB-anti-fluorescein, Roche) and colorimetric detection (DIG: NBT/BCIP, fluorescein: Fast Red or INT/ BCIP, both Roche). For documentation, ISH tissues were observed and stored in 75\% glycerol. Selected ISH samples (complete small sponges or parts of tissue) were embedded in an epoxy-based resin and sectioned ( $5 \mu \mathrm{m}$ thickness) using a Leica Ultracut microtome. The slidemounted sections were documented using a Nikon DSU3 microscope. Focused images of image stacks were generated with the Helicon Focus software (Helicon Soft).

\section{Ethics statement}

No ethical approval was required for any of the experimental research described here.

\section{Availability of supporting data}

The data sets supporting the results of this article are available in the Compagen repository [65], (genome assembly: SCIL_WGA_130802; coding sequences: SCIL_TCDS_130802, LCOM_T-CDS_130802; proteins: SCIL_PCDS_130802, LCOM_P-CDS_130802, http://compagen. org/datasets.html), in the European Nucleotide Archive [71], (CA- sequences: LN609531- LN609545, http:// www.ebi.ac.uk/ena/data/view/LN609531-LN609545), and in the Open Data LMU repository [72], (phylogenetic dataset and phylogenetic trees: doi:10.5282/ubm/data.63, http://data.ub.uni-muenchen.de/63).

The genomic and transcriptomic datasets of calcareous sponges used here are described by Fortunato et al. [29].

\section{Additional files}

Additional file 1: Calcein-stained triactine (18 h). Arrow: Enhanced calcite deposition at the unpaired angle, which could frequently be observed. pa: paired actines; upa: unpaired actines.

Additional file 2: Protein sequences of calcarean CAs. Signal peptides are shown in lower case. The three zinc-binding histidines or substitutions in homologous positions are shown bold and underlined. Predicted hydrophobic stretches (potential membrane embedded domains) are underlined. For LCAs, additional identified Pfam domains are bold and italics

Additional file 3: 15 active sites, previously reported to be conserved among active CA [9]. Note the shared substitutions of human (Hsa) CARPs (CAVIII, X, XI) and L-CAs. Two of the zinc-binding histidines are substituted by Argenine (R) and Glutamine (Q), respectively. +: active site hydrogen network, Z: zinc-binding histidine. (PDF 98 kb)

Additional file 4: ISH of CAs in L. complicata $(a, b)$ and S. ciliatum (c-h). (a,b) scl-CAs L. complicata: LcoCA1, LcoCA3). Expressing cells occur more densely at buds (formation of new tubes, see arrows). (c) scl-CA2 expressing cells are located in the mesohyl (cho: choanoderm, mes: mesohyl, pin: pinacoderm). (d,e) Weak expression (left, grey arrows) of scl-CA1 and scl-CA2 in posterior-most micromeres, and expression in juvenile sponges (right). (f) SciCA3 expressed in oocytes and early embryonic stages which are present in the radial tubes of the sponge (left, middle). Longer development of the color reaction reveals ubiquitous (rather than cell-type specific) signal, which is difficult to distinguish from 
background staining in other tissues and larvae (right). (g) SciCA7 expression in basal exo-pinacocytes (ex-pin, arrow) on the base of radial tubes

(section; atr: atrial cavity, rt: radial tubes). (h) SciCA4 is expressed in macromeres (black arrow) in larvae. All scale bars: $50 \mu \mathrm{m}$

Additional file 5: Accessions and sequence IDs of additional CA sequences included in phylogeny.

Additional file 6: Bayesian phylogeny of CAs. PP values given at the nodes, coloring and naming of clades corresponds to Figure 2.

Additional file 7: CA evolution reconciled with three hypotheses of animal relationships. Left: Classical concept, middle: "Coelenterata" [41], right: basal Ctenophora [42]. Filled dots: duplication events giving rise to paralogs; unfilled dots: duplication with speciation (origin of orthologs); dotted lines: gene loss in sisterclade. The evolution of scl-CA and LCA is highlighted. CAL: Calcarea, DEM: Demospongiae HEX: Hexactinellida; HOM: Homoscleromorpha; Aqu: Amphimedon queenslandica; Ava: Aphrocallistes vastus; Awi: Astrosclera willeyana; Emu: Ephydatia muelleri; Hma: Hydra magnipapillata; Hsa: Homo sapiens; Lco: L. complicata; Nve: Nematostella vectensis; Mle: Mnemiopsis leydi; Oca: Oscarella carmela; Spu:

Strongylocentrotus purpuratus; Tad: Trichoplax adhaerens.

Additional file 8: Alignment (selected positions) for phylogenetic analyses.

Additional file 9: Primer sequences.

\section{Abbreviations}

aLRT: Approximate likelihood ratio test; BS: Bootstrap; CA: a-carbonic anhydrase; DIG: Digoxigenin; ISH: RNA in situ hybridization; PP: Posterior probability; scl-CA: Sclerocyte specific carbonic anhydrase.

\section{Competing interests}

The authors declare that they have no competing interests.

\section{Authors' contributions}

Conceived and designed the study: OV and MajA. Generated sequence assemblies and databases: MarA. Specimen sampling: MarA, MajA. Laboratory experiments: OV, KS, MajA. Data analysis: OV, MarA. Drafted manuscript: OV. Edited manuscript: MajA, OV with input from co-authors. All authors read and approved the final manuscript.

\section{Acknowledgments}

The authors thank Mary Laplante for copy-editing of the final manuscript. We thank Ana Riesgo, Sally Leys and Gonzalo Giribet for providing sequence data ahead of publication, as well as Scott Nichols and Dan Richter for providing unpublished Ephydatia muelleri data via the Compagen portal. Furthermore, we would like to thank Gert Wörheide for providing the computational hardware for the phylogenetic analyses and use of laboratory equipment; Michael Eigler for assistance in spicule measurements, and Dirk Erpenbeck for constructive comments on an earlier version of the manuscript.

OV wishes to thank Sofia Fortunato, Sven Leininger and Corina Guder for help in the lab and tips about in situ hybridization protocols and EMBO for providing a short-term fellowship (ASTF331 -2012) to Bergen. KS thanks Sars International Centre for Marine Molecular Biology for funding of Masters student research training in Bergen. OV and KS thank the Sars Centre as host institution for carrying out the experiments.

We acknowledge research funding from the Sars Centre to the Adamska lab and from the LMU München to OV.

Received: 11 July 2014 Accepted: 28 October 2014

Published online: 25 November 2014

\section{References}

1. Knoll AH: Biomineralization and Evolutionary History. In Biomineralization Reviews in Mineralogy \& Geochemistry, Volume 54. Edited by Dove PM, Weiner S, DeYoreo JJ.; 2003:329-356.

2. Murdock DJE, Donoghue PCJ: Evolutionary origins of animal skeletal biomineralization. Cells Tissues Organs 2011, 194(2-4):98-102.

3. Jackson DJ, Macis L, Reitner J, Degnan BM, Wörheide G: Sponge paleogenomics reveals an ancient role for carbonic anhydrase in skeletogenesis. Science (New York, NY) 2007, 316(5833):1893-1895.
4. Mann K, Wilt FH, Poustka AJ: Proteomic analysis of sea urchin (Strongylocentrotus purpuratus) spicule matrix. Proteome Sci 2010, 8:33.

5. Marie B, Joubert C, Tayalé A, Zanella-Cléon I, Belliard C, Piquemal D, Cochennec-Laureau N, Marin F, Gueguen Y, Montagnani C: Different secretory repertoires control the biomineralization processes of prism and nacre deposition of the pearl oyster shell. Proc Natl Acad Sci U S A 2012, 109(51):20986-20991.

6. Le Roy N, Marie B, Gaume B, Guichard N, Delgado S, Zanella-Cléon I, Becchi M, Auzoux-Bordenave S, Sire J-Y, Marin F: Identification of two carbonic anhydrases in the mantle of the European Abalone Haliotis tuberculata (Gastropoda, Haliotidae): phylogenetic implications. J Exp Zool B Mol Dev Evol 2012, 318(5):353-367.

7. Tripp BC, Smith K, Ferry JG: Carbonic anhydrase: new insights for an ancient enzyme. J Biol Chem 2001, 276(52):48615-48618.

8. Henry RP: Multiple Roles of Carbonic Anhydrase in Cellular Transport and Metabolism. Annu Rev Physiol 1996, 58(1):523-538.

9. Hewett-Emmett D, Tashian RE: Functional diversity, conservation, and convergence in the evolution of the alpha-, beta-, and gamma-carbonic anhydrase gene families. Mol Phylogenet Evol 1996, 5(1):50-77.

10. Aspatwar A, Tolvanen ME, Parkkila S: Phylogeny and expression of carbonic anhydrase-related proteins. BMC Mol Biol 2010, 11:25.

11. Bertucci A, Moya A, Tambutté S, Allemand D, Supuran CT, Zoccola D: Carbonic anhydrases in anthozoan corals-A review. Bioorg Med Chem 2013, 21(6):1437-1450.

12. Aspatwar A, Tolvanen MEE, Ortutay C, Parkkila S: Carbonic Anhydrase related Proteins: Molecular Biology and Evolution. In Carbonic Anhydrase: Mechanism, Regulation, Links to Disease, and Industrial Applications, Volume 75. Edited by Frost SC, McKenna R. Netherlands: Springer; 2014:135-156.

13. Livingston BT, Killian CE, Wilt F, Cameron A, Landrum MJ, Ermolaeva O, Sapojnikov V, Maglott DR, Buchanan AM, Ettensohn CA: A genome-wide analysis of biomineralization-related proteins in the sea urchin Strongylocentrotus purpuratus. Dev Biol 2006, 300(1):335-348.

14. Moya A, Tambutté S, Bertucci A, Tambutté E, Lotto S, Vullo D, Supuran CT, Allemand D, Zoccola D: Carbonic anhydrase in the scleractinian coral Stylophora pistillata: Characterization, localization, and role in biomineralization. J Biol Chem 2008, 283(37):25475-25484.

15. Rahman MA, Oomori T, Uehara T: Carbonic anhydrase in calcified endoskeleton: Novel activity in biocalcification in Alcyonarian. Mar Biotechnol 2007, 10(1):31-38.

16. Tambutté S, Tambutté E, Zoccola D, Caminiti N, Lotto S, Moya A, Allemand D, Adkins J: Characterization and role of carbonic anhydrase in the calcification process of the azooxanthellate coral Tubastrea aurea. Mar Biol 2007, 151(1):71-83.

17. Manuel M: Phylogeny and evolution of calcareous sponges. Can J Zool 2006, 84:225-241.

18. Woodland W: Memoirs: Studies in Spicule Formation: I.-The Development and Structure of the Spicules in Sycons: with Remarks on the Conformation, Modes of Disposition and Evolution of Spicules in Calcareous Sponges generally. Q J Microsc Sci 1905, 49(194):231-282.

19. Minchin EA: Materials for a monograph of the Ascons. II: - The formation of spicules in the genus Leucosolenia, with some notes on the histology of the sponges. Q J Microsc Sci 1908, 52(3):301-355.

20. Ledger PW, Jones WC: Spicule formation in calcareous sponge Sycon ciliatum. Cell Tissue Res 1977, 181(4):553-567.

21. Ledger PW: Septate junctions in the calcareous sponge Sycon ciliatum. Tissue Cell 1975, 7(1):13-18.

22. Jones WC, Ledger PW: The effect of diamox and various concentrations of calcium on spicule secretion in the calcareous sponge Sycon ciliatum. Comp Biochem Physiol A Physiol 1986, 84(1):149-158.

23. Müller WEG, Wang X, Grebenjuk VA, Korzhev M, Wiens M, Schlossmacher U, Schröder HC: Common genetic denominators for $\mathrm{Ca}++-$ based skeleton in Metazoa: role of osteoclast-stimulating factor and of carbonic anhydrase in a calcareous sponge. PLoS One 2012, 7(4):e34617.

24. Müller WEG, Schlossmacher U, Schröder HC, Lieberwirth I, Glasser G, Korzhev M, Neufurth M, Wang X: Enzyme-accelerated and structure-guided crystallization of calcium carbonate: Role of the carbonic anhydrase in the homologous system. Acta Biomater 2014, 10(1):450-462.

25. Moya A, Huisman L, Ball EE, Hayward DC, Grasso LC, Chua CM, Woo HN, Gattuso JP, Forêt S, Miller DJ: Whole transcriptome analysis of the coral Acropora millepora reveals complex responses to $\mathrm{CO} 2$-driven 
acidification during the initiation of calcification. Mol Ecol 2012, 21(10):2440-2454.

26. Marie B, Jackson DJ, Ramos-Silva P, Zanella-Cléon I, Guichard N, Marin F: The shell-forming proteome of Lottia gigantea reveals both deep conservations and lineage-specific novelties. FEBS J 2013, 280(1):214-232.

27. Fortunato S, Adamski M, Bergum B, Guder C, Jordal S, Leininger S, Zwafink C, Rapp HT, Adamska M: Genome-wide analysis of the sox family in the calcareous sponge Sycon ciliatum: multiple genes with unique expression patterns. EvoDevo 2012, 3(1):14.

28. Leininger S, Adamski M, Bergum B, Guder C, Liu J, Laplante M, Bråte J, Hoffmann F, Fortunato S, Jordal S, Rapp HT, Adamska M: Developmental gene expression provides clues to relationships between sponge and eumetazoan body plans. Nat Commun 2014, 5:3905.

29. Fortunato SA, Adamski M, Ramos OM, Leininger S, Liu J, Ferrier DE, Adamska M: Calcisponges have a ParaHox gene and dynamic expression of dispersed NK homeobox genes. Nature 2014, 514(7524):620-623.

30. Ilan M, Aizenberg J, Gilor O: Dynamics and growth patterns of calcareous sponge spicules. Proc R Soc Lond B Biol Sci 1996, 263(1367):133-139.

31. Petersen TN, Brunak S, von Heijne G, Nielsen H: SignalP 4.0: discriminating signal peptides from transmembrane regions. Nat Meth 2011, 8(10):785-786.

32. TMHMM Server v. 2.0. http://www.cbs.dtu.dk/services/TMHMM-2.0/.

33. Emanuelsson $\mathrm{O}$, Nielsen $\mathrm{H}$, Brunak $\mathrm{S}$, von Heijne G: Predicting subcellular localization of proteins based on their $\mathrm{N}$-terminal amino acid sequence. J Mol Biol 2000, 300(4):1005-1016

34. Finn RD, Mistry J, Schuster-Böckler B, Griffiths-Jones S, Hollich V, Lassmann T, Moxon S, Marshall M, Khanna A, Durbin R, Eddy SR, Sonnhammer ELL, Bateman A: Pfam: clans, web tools and services. Nucleic Acids Res 2006, 34(Database issue):D247-D251.

35. Jones WC: Spicule Formation and Corrosion in recently Metamorphosed Sycon ciliatum (O. Fabricius). In Fourth European Marine Biology Symposium, Volume 4. Edited by Crisp DJ. Cambridge, UK: Cambridge University Press; 1971:301-320

36. Li B, Dewey CN: RSEM: accurate transcript quantification from RNA-Seq data with or without a reference genome. BMC Bioinformatics 2011, 12:323.

37. Anders $S$, Huber W: Differential expression analysis for sequence count data. Genome Biol 2010, 11(10):R106.

38. Darriba D, Taboada GL, Doallo R, Posada D: ProtTest 3: fast selection of best-fit models of protein evolution. Bioinformatics 2011, 27(8):1164-1165

39. Ronquist F, Huelsenbeck JP: MrBayes 3: Bayesian phylogenetic inference under mixed models. Bioinformatics 2003, 19(12):1572-1574.

40. Nosenko T, Schreiber F, Adamska M, Adamski M, Eitel M, Hammel J, Maldonado M, Müller WEG, Nickel M, Schierwater B, Vacelet J, Wiens M, Wörheide G: Deep metazoan phylogeny: when different genes tell different stories. Mol Phylogenet Evol 2013, 67(1):223-233.

41. Philippe $H$, Derelle R, Lopez P, Pick K, Borchiellini C, Boury-Esnault N, Vacelet J, Renard E, Houliston E, Queinnec E, Da Silva C, Wincker P, Le Guyader H, Leys S, Jackson DJ, Schreiber F, Erpenbeck D, Morgenstern B, Wörheide G, Manuel M: Phylogenomics revives traditional views on deep animal relationships. Curr Biol 2009, 19(8):706-712.

42. Ryan JF, Pang K, Schnitzler CE, Nguyen A-D, Moreland RT, Simmons DK, Koch BJ, Francis WR, Havlak P, Program NCS, Smith SA, Putnam NH, Haddock SHD, Dunn CW, Wolfsberg TG, Mullikin JC, Martindale MQ, Baxevanis AD: The genome of the ctenophore Mnemiopsis leidyi and its implications for cell type evolution. Science (New York, NY) 2013, 342(6164):1242592.

43. Conow C, Fielder D, Ovadia Y, Libeskind-Hadas R: Jane: a new tool for the cophylogeny reconstruction problem. Algorithm Mol Biol 2010, 5:16.

44. Aizenberg J, Hanson J, llan M, Leiserowitz L, Koetzle TF, Addadi L, Weiner S: Morphogenesis of calcitic sponge spicules - a role for specialized proteins interacting with growing crystals. FASEB J 1995, 9(2):262-268.

45. Furla P, Galgani I, Durand I, Allemand D: Sources and mechanisms of inorganic carbon transport for coral calcification and photosynthesis. J Exp Biol 2000, 203(Pt 22):3445-3457.

46. Wörheide G, Hooper J: Calcarea from the Great Barrier Reef. 1: Cryptic Calcinea from Heron Island and Wistari Reef (Capricorn-Bunker Group). Mem Queensl Mus 1999, 43(2):859-891.

47. Parker MD, Boron WF: The divergence, actions, roles, and relatives of sodium-coupled bicarbonate transporters. Physiol Rev 2013, 93(2):803-959.

48. Zoccola D, Tambutté E, Kulhanek E, Puverel S, Scimeca J-C, Allemand D, Tambutté S: Molecular cloning and localization of a PMCA P-type calcium
ATPase from the coral Stylophora pistillata. Biochim Biophys Acta 2004, 1663(1-2):117-126

49. Voigt $\mathrm{O}$, Wülfing $\mathrm{E}$, Wörheide $\mathrm{G}$ : Molecular phylogenetic evaluation of classification and scenarios of character evolution in Calcareous Sponges (Porifera, Class Calcarea). PLoS One 2012, 7(3):e33417.

50. Guindon S, Dufayard J-F, Lefort V, Anisimova M, Hordijk W, Gascuel O: New algorithms and methods to estimate maximum-likelihood phylogenies: assessing the performance of PhyML 3.0. Syst Biol 2010, 59(3):307-321.

51. Manuel M, Borchiellini C, Alivon E, Le Parco Y, Vacelet J, Boury-Esnault N: Phylogeny and evolution of calcareous sponges: Monophyly of Calcinea and Calcaronea, high level of morphological homoplasy, and the primitive nature of axial symmetry. Syst Biol 2003, 52(3):311-333.

52. Manuel M, Borchiellini C, Alivon E, Boury-Esnault N: Molecular phylogeny of calcareous sponges using $18 \mathrm{~S}$ rRNA and $28 \mathrm{~S}$ rRNA sequences. Boll Mus Ist Biol Univ Genova 2004, 68:449-461.

53. Smith AM, Berman J, Key JMM, Winter DJ: Not all sponges will thrive in a high-CO2 ocean: Review of the mineralogy of calcifying sponges. Palaeogeogr Palaeoclimatol Palaeoecol 2013, 392:463-472.

54. Altschul SF, Gish W, Miller W, Myers EW, Lipman DJ: Basic local alignment search tool. J Mol Biol 1990, 215(3):403-410.

55. CBS Prediction Servers. http://www.cbs.dtu.dk/services/.

56. GenBank. http://www.ncbi.nlm.nih.gov/genbank/.

57. Nichols SA, Dirks W, Pearse JS, King N: Early evolution of animal cell signaling and adhesion genes. Proc Natl Acad Sci U S A 2006, 103(33):12451-12456.

58. Sodergren E, Weinstock GM, Davidson EH, Cameron RA, Gibbs RA, Angerer RC, Angerer LM, Arnone MI, Burgess DR, Burke RD, Coffman JA, Dean M, Elphick MR, Ettensohn CA, Foltz KR, Hamdoun A, Hynes RO, Klein WH, Marzluff W, McClay DR, Morris RL, Mushegian A, Rast JP, Smith LC, Thorndyke MC, Vacquier VD, Wessel GM, Wray G, Zhang L, Elsik CG, et al: The genome of the sea urchin Strongylocentrotus purpuratus. Science (New York, NY) 2006, 314(5801):941-952.

59. Putnam N, Srivastava M, Hellsten U, Dirks B, Chapman J, Salamov A, Terry A, Shapiro H, Lindquist E, Kapitonov V, Jurka J, Genikhovich G, Grigoriev I, Lucas S, Steele R, Finnerty J, Technau U, Martindale M, Rokhsar D: Sea anemone genome reveals ancestral eumetazoan gene repertoire and genomic organization. Science (New York, NY) 2007, 317(5834):86-94.

60. Srivastava M, Begovic E, Chapman J, Putnam NH, Hellsten U, Takeshi K, Kuo A, Mitros T, Salamov A, Carpenter ML, Signorovitch AY, Moreno MA, Kamm K, Grimwood J, Schmutz J, Shapiro H, Grigoriev IV, Buss LW, Schierwater B, Dellaporta SL, Rokhsar DS: The Trichoplax genome and the nature of placozoans. Nature 2008, 454(7207):955.

61. Chapman JA, Kirkness EF, Simakov O, Hampson SE, Mitros T, Weinmaier T, Rattei T, Balasubramanian PG, Borman J, Busam D, Disbennett K, Pfannkoch C, Sumin N, Sutton GG, Viswanathan LD, Walenz B, Goodstein DM, Hellsten U, Kawashima T, Prochnik SE, Putnam NH, Shu S, Blumberg B, Dana CE, Gee L, Kibler DF, Law L, Lindgens D, Martinez DE, Peng J, et al: The dynamic genome of Hydra. Nature 2010, 464(7288):592-596.

62. Srivastava M, Simakov O, Chapman J, Fahey B, Gauthier ME, Mitros T, Richards GS, Conaco C, Dacre M, Hellsten U, Larroux C, Putnam NH, Stanke M, Adamska M, Darling A, Degnan SM, Oakley TH, Plachetzki DC, Zhai Y, Adamski M, Calcino A, Cummins SF, Goodstein DM, Harris C, Jackson DJ, Leys SP, Shu S, Woodcroft BJ, Vervoort M, Kosik KS, et al: The Amphimedon queenslandica genome and the evolution of animal complexity. Nature 2010, 466(7307):720-726

63. Nichols SA, Roberts BW, Richter DJ, Fairclough SR, King N: Origin of metazoan cadherin diversity and the antiquity of the classical cadherin/ B-catenin complex. Proc Natl Acad Sci 2012, 109(32):13046-13051.

64. Riesgo A, Farrar N, Windsor PJ, Giribet G, Leys SP: The analysis of eight transcriptomes from all Porifera classes reveals surprising genetic complexity in sponges. Mol Biol Evol 2014, 31(5):1102-1120.

65. Compagen. http://www.compagen.org.

66. Hemmrich G, Bosch TCG: Compagen, a comparative genomics platform for early branching metazoan animals, reveals early origins of genes regulating stem-cell differentiation. Bioessays 2008, 30(10):1010-1018.

67. Metazome v3.0. http://www.metazome.net.

68. Katoh K, Standley DM: MAFFT multiple sequence alignment software version 7: improvements in performance and usability. Mol Biol Evol 2013, 30(4):772-780

69. Castresana J: Selection of conserved blocks from multiple alignments for their use in phylogenetic analysis. Mol Biol Evol 2000, 17(4):540-552. 
70. Wörheide G, Dohrmann M, Erpenbeck D, Larroux C, Maldonado M, Voigt O, Borchiellini C, Lavrov DV: Deep Phylogeny and Evolution of Sponges (Phylum Porifera). In Adv Mar Biol, Volume 61. San Diego, USA: Elsevier Academic Press Inc; 2012:1-78.

71. European Nucleotide Archive. http://www.ebi.ac.uk/ena

72. Open Data LMU. http://data.ub.uni-muenchen.de.

doi:10.1186/s12862-014-0230-z

Cite this article as: Voigt et al:: Calcareous sponge genomes reveal complex evolution of a-carbonic anhydrases and two key

biomineralization enzymes. BMC Evolutionary Biology 2014 14:230.

\section{Submit your next manuscript to BioMed Central} and take full advantage of:

- Convenient online submission

- Thorough peer review

- No space constraints or color figure charges

- Immediate publication on acceptance

- Inclusion in PubMed, CAS, Scopus and Google Scholar

- Research which is freely available for redistribution 